TAPROBANICA, ISSN 1800-427X. June, 2014. Vol. 06, No. 01: pp. 7-11, 1 pl.

(C) Research Center for Climate Change, University of Indonesia, Depok, Indonesia \& Taprobanica Private Limited, Homagama, Sri Lanka

http://www.sljol.info/index.php/tapro

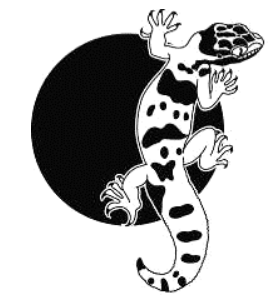

\title{
ACTIVITY BUDGET AND PERCH CHARACTERISTICS OF Pseudophilautus popularis (MANAMENDRA-ARACHCHI \& PETHIYAGODA, 2005) (AMPHIBIA: RHACOPHORIDAE) DURING THE BREEDING SEASON
}

Section Editor: $\quad$ Enrique La Marca $\quad$ Submitted: 30 November 2013, Accepted: 15 March 2014

\author{
Salindra K. Dayananda ${ }^{1}$ and Deepthi D. Wickramsinghe ${ }^{2}$ \\ ${ }^{1}$ Key Laboratory of Tropical Forest Ecology, Xishuangbanna Tropical Botanic Garden, University of Chinese \\ Academy of Scienses, Yunnan, China; E-mail: kasunkent@gmail.com \\ ${ }^{2}$ Department of Zoology, Faculty of Science, University of Colombo, Colombo 03, Sri Lanka \\ E-mail: deepthi@zoology.cmb.ac.lk
}

\begin{abstract}
This study reports activity budget and perch characteristics of the Sri Lankan endemic shrub frog Pseudophilautus popularis in a wetland-home garden setting in an urban area. Thirty-two frogs were studied from 18:30-06:00h and $45 \%$ of the time they were found to be stationary without any activity. The highest percentage of time was utilised for calling and courtship (52\%). This study reveals that the frogs occupy different heights during their nightly activity period, starting from the ground level and gradually moving up among the vegetation. They were reported to reach the maximum heights around 23:00h, remaining there for nearly two hours and then retreating downwards towards the dawn. The results emphasize the importance of maintaining diversity of vegetation especially in terms of stratification in ensuring habitat quality to conserve this species.
\end{abstract}

Key words: behavior, endemic, home gardens, shrub frog, Sri Lanka, urban ecosytems

\section{Introduction}

Even though the taxonomy and phylogeny of amphibians (Manamendra-Arachchi \& Meegaskumbura, 2012; Wickramasinghe et al., 2013) are well studied in Sri Lanka, relatively little attention has been paid to ecological and behavioral characterization. Other than for vocalization (Samarasinghe, 2011) and some information on breeding (Bahir et al., 2005; Karunarathna \& Amarasinghe, 2007, 2010), literature on the biology and ecology of $P$. popularis is not available. The Common shrub-frog Pseudophilautus popularis (Manamendra-Arachchi \& Pethiyagoda, 2005) was described in 2005 and information on taxonomic features and distribution has been published. In the context of global amphibian decline and increasingly evident threats to amphibian fauna (Stuart et al., 2004), it is of vital importance to report how frogs interact with each other and with the environment in which they live (Zug et al., 2001). Furthermore, understanding behavior and habitat 
characteristics is particularly essential in conservation management of animals (Duellman \& Trueb, 1986; Biju, 2003). Thus, the present study was designed to focus on some aspects of both behavior and ecology of $P$. popularis. One objective of this study was to investigate and describe different activities exhibited by the frogs and present these as an activity budget. Secondly, recognizing the importance of microhabitat use among vegetation for shrub frogs, studying perching characteristics of frogs in relation to time and space was also undertaken. In addition, some behavioral patterns were studied in detail.

\section{Materials and Methods}

This frog mainly inhabits the low country wet zone and is common in wetlands, anthropogenic habitats and at forest edges, but never in forest interiors. The study area was a block of private land near Bolgoda wetland complex $\quad\left(79^{\circ} 52^{\prime}-79^{\circ} 59^{\prime} \mathrm{N}, 6^{\circ} 42^{\prime}-06^{\circ} 51^{\prime} \mathrm{E}\right)$ which is situated in the Western Province of Sri Lanka. The mean annual rainfall is $\sim 2500 \mathrm{~mm}$, and the annual temperature varies from 27-34 ${ }^{\circ} \mathrm{C}$. The study site consists of a mosaic of home gardens, marshes, reed beds, abandoned paddy fields and wet scrublands. This site was selected because of the richness in different microhabitat types and on the presence of a healthy frog population. It was noted that the best time to observe frog activity is after 1800 h.

During a four month period (March-June 2009), 30 nights (one hour per night with time varied from 1830-0530h) were spent in the field. Some random observations were carried out during the day time to see whether frogs were visible. These months fall within the intermonsoon rain period and coincides with the breeding season. They are therefore ideal for observing frogs. Surveys were conducted along randomly selected transects with varied transect lengths from $200-800 \mathrm{~m}$. The observations were done by the naked eye and red colour headlights were used to minimize disturbances to animals. Gender determination of the observed frogs was carried out at the end of the observation period of each night by carefully capturing them and recording sex. All captured frogs were released to their habitat immediately. Some individuals were photographed and different postures were drawn.

\section{Results}

Time budget for behavioral activities: Once an animal was spotted, its behavior was monitored continuously for one hour or until the animal moved and disappeared. Focal animal sampling technique (Altmann, 1974) was applied to collect behavioral data. Activities were divided into seven categories and the time spent for each was recorded using a stop watch: resting (no movement on the substrate), walking (movement on a substrate), jumping (jump from one spot to another), climbing (moving up among the shrubs), cleaning (using the limbs to clean body surface), calling (emitting vocal signals by males), agonistic (fighting with another frog), and sexual behavior (male reaching the female, mounting and amplexus).

The total duration spent on observing was 17 hours, 56 minutes, and 57 seconds. Obviously, calling and agonistic behaviors were shown only by males. For a little less than half of the time (45.2\% of total time) the frogs were stationary and inactive (Table 1 ). When active, they spent the majority of their time on calling and sexual behavior $(52 \%)$. All other activities combined represented only $3 \%$ of total activity budget. They were rarely seen foraging and hence that activity is not included in the budget. It was found that males exhibit territorial behavior and did not move beyond a radius of $5 \mathrm{~m} \quad(n=29)$. Frogs of both sexes were, in general, found to be solitary. A gravid female and a couple in amplexus are shown in figures 1 and 2. In this study, special attention was paid to document calling behavior. Males always called from a place above ground level: while perching on leaf edges or the branches of shrubs. Perch height ranged from $15 \mathrm{~cm}$ to $180 \mathrm{~cm}$ above the ground level. Males were never seen on the ground. Females always perched on plant leaves ranging from a height of $7-15 \mathrm{~cm}$ from ground level. Males emitted two types of calls: advertisement calls and elevated advertisement calls, and both were discontinuous calls. During these calling activities, the posture of males showed a clear difference (Figs. 3 and 4). Generally, during advertisement calls, the body of the frog was positioned in such a way as to raise the anterior part of the body above the substrate at an angle and then they emitted short scattered calls. In contrast, when emitting elevated advertisement calls, which consisted of long scattered notes, the body was more or less parallel to the 
substrate. The duration and intensity of calls were shown to increase when the encounter got closer. Frogs of Pseudophilautus popularis showed variation of perching characteristics over time (Fig. 5). Frogs climbed up in the shrubs and occupied various strata until around $2300 \mathrm{~h}$ when they attained the highest level. In general, the frogs remained at the highest level for nearly 2 hours and then showed a clear retreat downwards after $0200 \mathrm{~h}$.

Table 1: Activity budget of Pseudophilautus popularis $(n=32)$, abbreviations: TTS $=$ Total time spent (sec.) and PTS = Percentage time spent.

\begin{tabular}{lcc}
\hline \multicolumn{1}{c}{ Activity } & TTS (sec.) & PTS \% \\
\hline No movement & 29234 & 45.2 \\
Walking & 105 & 0.2 \\
Jumping & 49 & 0.1 \\
Climbing & 22 & 0.0 \\
Cleaning & 79 & 0.0 \\
Calling & 17548 & 27.1 \\
Agonistic & 1380 & 2.1 \\
Courtship & 16200 & 25.0 \\
\hline Total & $\mathbf{6 4 6 1 7}$ & $\mathbf{1 0 0}$ \\
\hline
\end{tabular}

Characteristics of perching: When a frog was found perched among vegetation the time of the encounter and the frog's relative position was recorded. This was carried out by cautiously following the frog and measuring the perching height from the ground level using a meter tape. Maximum care was taken not to disturb the frog and to get accurate measurements.

During this study, a total of 32 Pseudophilautus popularis (29 males and 3 females) were observed and studied. During the daytime, frogs were not encountered. Results for both sexes were pooled for analysis. Three main combat techniques were observed - squeezing by clasping the opponent, pushing against a hard surface and overturning the opponent while clasping. The most common combat technique was squeezing the opponent. Calling did not cease during combat, but the rate of call was decreased. Finally the weaker male was scared away. Several cleaning events were observed in both male and female individuals, especially after fighting. The attached soil particles were removed by the use of both forelimbs and hind limbs by the males. But the skin was rubbed regularly by both the male and females during the observation.

\section{Discussion}

This study has obtained exploratory data on some behavioral activities and perch characteristics of Pseudophilautus popularis during the breeding season. Since documentation on activity budgets is rare for shrub frogs, these results are of great importance in understanding their behavior. Evidently, during the night time the frogs are partially inactive, spending nearly half of the time stationary. Calling and courtship accounted for the majority of the time. Information on activity budgets of frogs are rare and at least one study (on Colostethus beebei, with $40 \%$ of total time) shows that considerable time may be spent on vocalization (Bourne et al., 2001).

Secondly, interpretation of habitat use data reveals the importance of different strata of the vegetation as microhabitats for frogs. Although our data is insufficient to confirm that selection of different microhabitat across the canopy could be influenced by resource choices of frogs (Ra et al., 2008), there could be several factors operating. These may include abundance of conspecifics (Galdino et al., 2008) and activities of the neighbor (Given, 1993). Brief notes on combat behavior were documented for the first time in Sri Lanka by Arak (1983). Males produce advertisement calls (Samarasinghe, 2011) with the intention of attracting females, but when another rival male is encountered within the range, there is a higher probability that fighting will occur. This phenomenon was documented by Arak (1983) in Pseudophilautus leucorhinus, an extinct shrub frog in Sri Lanka (MOE, 2012).

Bolgoda, our study site, is situated in an urban area and it was observed that the majority of land use in the area had been always under human influences. Some environmental changes which were frequently noted include the vast amount of vegetation clearing and removal, especially on private lands. This will obviously affect the essential elements of habitat quality on which amphibian fauna are directly dependent (Weerawardena et al., 2004; Weerawardena \& Russel, 2012). For instance, shade and moisture are some of the major factors affecting the ecological distribution of amphibians (Duellman \& Trueb, 1986) which will be altered if the vegetation is disturbed. Habitat loss and degradation are by far the 
greatest threat to amphibians at present (Cushman, 2006; Mendelson et al., 2006; Pethiyagoda et al., 2006) thus posing direct impacts on them (Beebee \& Griffiths, 2005; Beebee, 1996). This study indicates the importance of maintaining vegetation structure as an essential habitat component for shrub frog $P$. popularis especially in anthropogenic habitats.

Even though $P$. popularis is categorized as a Least Concern level in the National Red List 2012 (MOE, 2012), it is evident that this species could be threatened if the present deleterious impacts continue. This synanthropic species (Manamendra-Arachchi \& Pethiyagoda, 2005) is only encountered within anthropogenic habitats (Manamendra-Arachchi \& Pethiyagoda, 2005), wetlands (Karunarathna et al., 2010) and forest edges (Kumara \& Ukuwela, 2009). Due to the unique habitat preferences of this frog, considerable conservation measures should apply to ensure the remaining population of this species. Overall, the results are only preliminary; thus, a more detailed study should be conducted to cover more areas in pristine as well as disturbed habitats. However, more information is needed on endemic species to warrant elaborative scientific investigations.

\section{Acknowledgements}

We are grateful to the Field Ornithology Group of Sri Lanka (FOGSL) and University of Colombo for logistical support. We would like to thank Sampath Arambepola, Sameera Areyarathna, Chathura Samaranayaka, and Menen Jayarathna for field assistance, Gayan Ratnasekara, Sameera Karunarathna, Anslem de Silva, and Wipula Yapa for valuable comments.

\section{Literature cited}

Altmann, J., 1974. Observational study of behavior: sampling methods. Behaviour, 49 (3): 227-267.

Arak, A., 1983. Vocal interactions, call matching and territoriality in a Sri Lankan treefrog, Philautus leucorhinus (Rhacophoridae). Animal Behaviour, 31 (1): 292-302.

Bahir, M. M., M. Meegaskumbura, K. Manamendra-Arachchi, C. J. Schneider, and R. Pethiyagoda, 2005. Reproduction and terrestrial direct development in Sri Lankan shrub frogs
(Ranidae: Rhacophorinae: Philautus). Pp. 339350. In: D.C.J. Yeo, P.K.L. $\mathrm{Ng}$ and R. Pethiyagoda (Eds.), Contribution to biodiversity exploration and research in Sri Lanka. The Raffles Bulletin of Zoology, Supplement No. 12.

Beebee, T. J. C., 1996. Ecology and Conservation of Amphibians. Chapmen and Hall, London: 214.

Beebee, T. J. C. and R. A. Griffiths, 2005. The amphibian decline crisis: a watershed for conservation biology? Biological Conservation, 125 (4) : 271-285.

Biju, S. D., 2003. Reproductive mode in the shrub frog Philautus glandulosus (Jerdon, 1853) (Anura: Rhacophoridae). Current Science, 84 (3): 283-284.

Bourne, G. R., A. C. Collins, A. M. Holder, and C. L. McCarthy, 2001. Vocal communication and reproductive behavior of the frog Colostethus beebei in Guyana. Journal of Herpetology, 35 (2): 272-281.

Cushman, S. A., 2006. Effects of habitat loss and fragmentation on amphibians: a review and prospectus. Biological conservation, 128 (2): 231-240.

Duellman, W. E. and L. Trueb, 1986. Biology of Amphibians. McGraw-Hill Book Co., New York: 670.

Galdino, L. B., C. A. B. Carvalho, R. R. V. Menezes, and M. A. Nascimento, 2008. Habitat use by a tree frog species of Scinax (Amphibia, Hylidae) at an urban forest fragment from southeastern Brazil. In: Iheringia, Série Zoologia, 98 (3): 412-415.

Given, M. F., 1993. Vocal interactions in Bufo woodhousii fowleri. Journal of Herpetology, 27:447-452.

Karunarathna, D. M. S. S. and A. A. T. Amarasinghe, 2007. Observations on the breeding behavior of Philautus regius Manamendra-Arachchi and Pethiyagoda, 2005 (Amphibia: Ranidae: Rhacophorinae) in Nilgala, Monaragala District in Sri Lanka. Russian Journal of Herpetology, 14: 133-136.

Karunarathna, D. M. S. S. and A. A. T. Amarasinghe, 2010. Field Observations on the Reproductive Behaviour of Philautus popularis Manamendra-Arachchi \& Pethiyagoda, 2005 
(Amphibia: Rhacophoridae). Sauria, 32 (3): 5762 .

Karunarathna, D. M. S. S., A. A. T. Amarasinghe, D. E. Gabadage, M. M. Bahir and L. E. Harding. 2010. Current status of faunal diversity in Bellanwila-Attidiya sanctuary, Colombo District Sri Lanka. Taprobanica, 2: 48-63.

Kumara, D. M. N. P. and K. D. B. Ukuwela, 2009. A survey on the amphibians of Ambagamuwa, a tropical wet mid- midland area in Sri Lanka. Herpetology Notes, 2 (2): 81-85.

Manamendra-Arachchi, K. and M. Meegaskumbura, 2012. The taxonomy and conservation status of amphibians in Sri Lanka. Pp. 88-91. In: D.K. Weerakoon and S. Wijesundara (Eds.), The National Red List 2012 of Sri Lanka: Conservation Status of the Fauna and Flora. Ministry of Environment, Colombo, Sri Lanka.

Manamendra-Arachchi, K. and R. Pethiyagoda, 2005. The Sri Lankan shrub-frogs of the genus Philautus Gistel, 1848 (Ranidae: Rhacophorinae), with description of 27 new species. Pp. 163-303. In: D.C.J. Yeo, P.K.L. Ng and R. Pethiyagoda (Eds.), Contribution to biodiversity exploration and research in Sri Lanka. The Raffles Bulletin of Zoology, Supplement No. 12.

Mendelson III, J. R., K. R. Lips, R. W. Gagliardo, G. B. Rabb, J. P. Collins, J. E. Diffendorfer, P. Daszak, R. Ibáñez D., K. C. Zippel, D. P. Lawson, K. M. Wright, S. N. Stuart, C. Gascon, H. R. da Silva, P. A. Burrowes, R. L. Joglar, E. La Marca, S. Lötters, L. H. du Preez, C. Weldon, A. Hyatt, J. V. Rodriguez-Mahecha, S. Hunt, H. Robertson, B. Lock, C. J. Raxworthy, D. R. Frost, R. C. Lacy, R. A. Alford, J. A. Campbell, G. Parra-Olea, F. Bolaños, J. J. C. Domingo, T. Halliday, J. B. Murphy, M. H. Wake, L. A. Coloma, S. L. Kuzmin, M. S. Price, K. M. Howell, M. Lau, R. Pethiyagoda, M. Boone, M. J. Lannoo, A. R. Blaustein, A. Dobson, R. A. Riffiths, M. L. Crump, D. B. Wake, and E. D. Brodie, 2006. Biodiversity. Confronting amphibian declines and extinctions. Science, 313 (5783): 48-48.

MOE 2012. The National Red List 2012 of Sri Lanka; Conservation Status of the Fauna and Flora. Ministry of Environment, Colombo, Sri Lanka: 476.
Pethiyagoda, R., K. Manamendra-Arachchi, M. M. Bahir, and M. Meegaskumbura, 2006. Sri Lankan Amphibians: Diversity, Uniqueness and Conservation. Pp. 125-133. In: C.N.B. Bambaradeniya (Eds.), Fauna of Sri Lanka: Status of Taxonomy, Research and Conservation. The World Conservation Union, Colombo, Sri Lanka and Government of Sri Lanka.

Ra, N. Y., H. C. Sung, S. Cheong, J. H. Lee, J. Eom, and D. Park, 2008. Habitat use and home range of the endangered gold-spotted pond frog (Rana chosenica). Zoological science, 25 (9): 894-903.

Samarasinghe, D. J. S., 2011. Description of the complex advertisement call of Pseudophilautus popularis (Manamendra-Arachchi \& Pethiyagoda, 2005) (Amphibia: Rhacophoridae), Zootaxa, 3002: 62-64.

Stuart, S., J. S. Chanson, N. A. Cox, B. E. Young, A. S. L. Rodrigues, D. L. Fischman, and R. W. Waller, 2004. Status and Trends of Amphibian Declines and Extinctions Worldwide. Science, 306 (5702), 1783-1786.

Weerawardhena, S. R. and A. P. Russell, 2012. Cover-dependent and -independent Anuran Amphibian Species in the Riverstone region, Knuckles Mountain Forest Range, Sri Lanka. Taprobanica, 4 (1): 12-19.

Weerawardhena, S. R., U. S. Amarasinghe, and S. W. Kotagama, 2004. Activity pattern and environmental variation of micro habitats of sixtoed green frog Euphlyctis hexadactylus Lesson 1843 (Anura: Ranidae) in Sri Lanka. The Herpetology of Sri Lanka: Current research. Lyriocephalus, 5 (1 \& 2): 111-129.

Wickramasinghe, L.J.M., D.R. Vidanapathirana, M.D.G. Rajeev, S.C. Ariyarathne, A.W.A. Chanaka, L.L.D. Priyantha, I.N. Bandara, and N. Wickramasinghe, 2013. Eight new species of Pseudophilautus (Amphibia, Anura, Rhacophoridae) from Sripada World Heritage Site (Peak Wilderness), a local amphibian hotspot in Sri Lanka. Journal of Threatened Taxa, 5 (4): 3789-3920.

Zug, G. R, L. J. Vitt, and J. P. Caldwel, 2001. Herpetology. An Introductory Biology of Amphibians and Reptiles ( $2^{\text {nd }}$ edition). The Academic Press: 680. 


\section{PLATE 2}

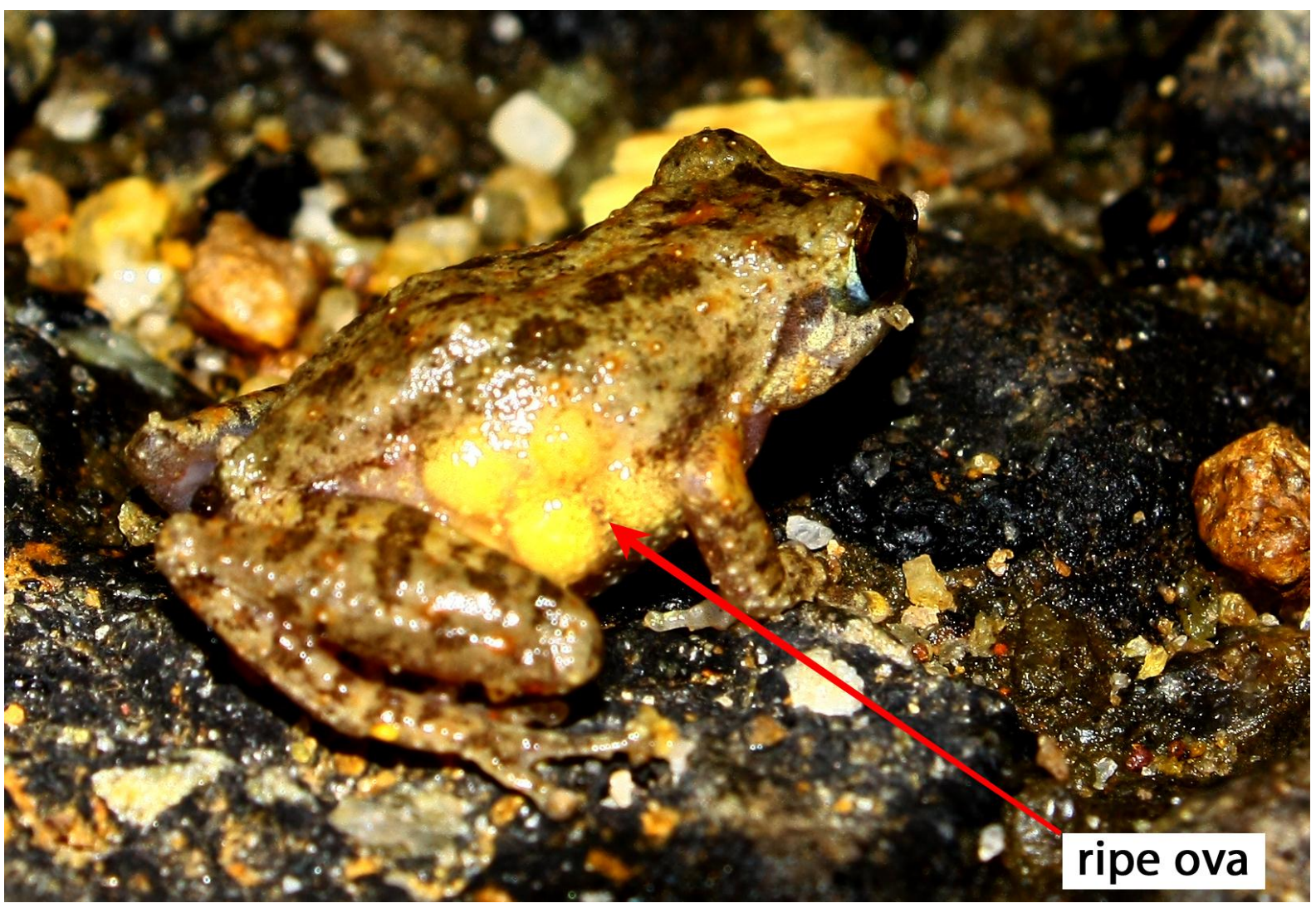

Figure 1: Gravid P. popularis female with ripe ova.

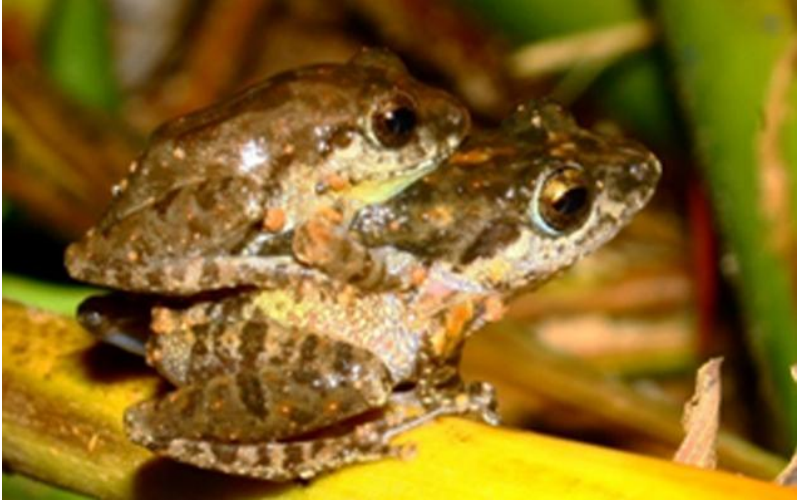

Figure 2: Couple in amplexus on a twig

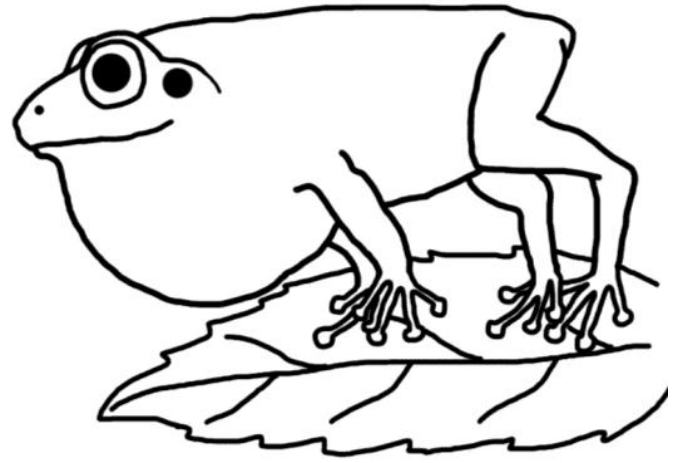

Figure 4: Elevated advertisement calling posture

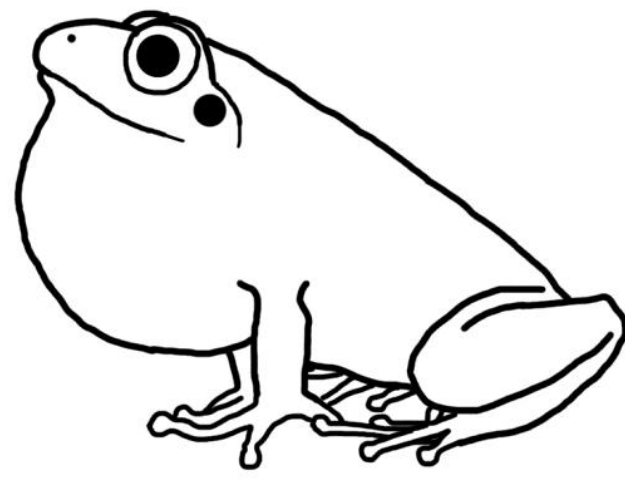

Figure 3: Advertisement calling posture

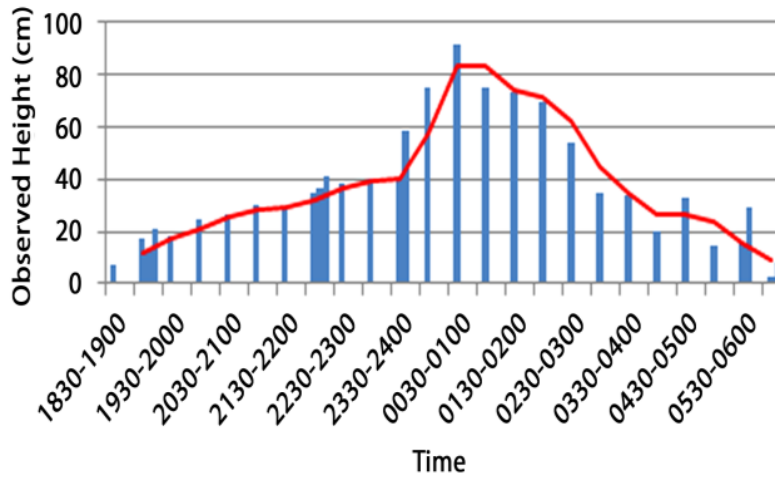

Figure 5: Variation in observed perched height level with time $(n=32)$ 